\title{
KNEE FLEXION AND EXTENSION STRENGTH IN YOUNG BRAZILIAN SOCCER PLAYERS: THE EFFECT OF AGE AND POSITION
}

original paper

( ) University School of Physical Education in Wroclaw

DOI: https://doi.org/10.5114/hm.2018.76076

CARLOS VINICIUS HERDY ${ }^{1,2,3}$, PAULIANA GALVAO ${ }^{2}$, GABRIEL COSTA E SILVA ${ }^{3}$, SARAH RAMOS ${ }^{3}$, ROBERTO SIMAO ${ }^{3}$, ANDRE PEDRINELLI ${ }^{4}$, SANDRO MANSUR $^{1}$, DANIEL GONCALVES ${ }^{3}$, VASSILIS PASCHALIS ${ }^{5}$

\author{
${ }^{1}$ Physical Education Department, Estácio de Sá University, Rio de Janeiro, Brazil \\ ${ }^{2}$ Doctoral Program in Epidemiology in Public Health, ENSP/FioCruz, Rio de Janeiro, Brazil \\ ${ }^{3}$ Physical Education Graduate Program, Federal University of Rio de Janeiro, Rio de Janeiro, Brazil \\ ${ }^{4}$ São Paulo FIFA Medical Centre of Excellence, São Paulo, Brazil \\ ${ }^{5}$ Department of Physical Education and Sport Science, National and Kapodistrian University of Athens, Athens, Greece
}

\section{ABSTRACT}

Purpose. To compare isokinetic knee flexors and extensors concentric muscle strength in young soccer players of different ages and playing positions.

Methods. Seventy-seven young male soccer players were divided into 3 age categories: U-15, U-17, and U-20, with the consideration of 4 game positions: goalkeepers, defenders, midfielders, and forwards. The concentric tests of the hamstrings (Hcon) and quadriceps (Qcon) were performed at 30\%, 60\%, and 180\%, and the ratio of $180 \% 30^{\circ}$ was calculated.

Results. The values of Qcon for the U-15 turned out significantly lower in comparison with the U-20 in $30 \% \mathrm{~s}$ and $180 \% \mathrm{~s}$ and in the $180^{\circ} / 30^{\circ}$ ratio. The Hcon values for the U-15 were significantly lower than for the U-20 at $30 \%$, $60 \%$, $180 \%$, as well as in the $180^{\circ} / 30^{\circ}$ ratio. Strength levels were shown to be significantly different between the 3 analysed categories. The goalkeepers presented with Qcon and Hcon values significantly higher than the other playing positions, regardless of the angular velocity used.

Conclusions. U-15, U-17, and U-20 athletes do not have the same level of strength. The goalkeepers demonstrated high strength values, suggesting the importance of specific training for each game position.

Key words: soccer, muscle strength dynamometer, athletes

\section{Introduction}

Soccer was institutionalized in 1863 by the Football Association and is a sport modality in great expansion. It can be considered the most popular sport of the world [1], attracting millions of people [2]. According to Burke and Hawley [3], there may be more than 120 million soccer players around the world. However, studies on soccer players' physical condition parameters are limited, and more research is still needed in this field.

Muscle strength is one of the most important physical fitness components whose efficiency directly affects soccer performance [4]. Tsiokanos et al. [5] point out that the movements that soccer players perform during games and training depend on the strength of the lower limbs, especially of the quadriceps and hamstring muscles. Therefore, knowledge of muscle strength profiles in players is important for appropriate prescription in order to achieve maximum performance [6].

Soccer players' strength was previously studied with such tests as vertical jump and squats [7-11]. In contrast to these indirect methods, some authors have observed that the isokinetic dynamometry test for strength evaluation can be considered a modern technological method

Correspondence address: Carlos Herdy, Physical Education Department, Estácio de Sá University, Rua Sargento João Lópes 1900, Jardim Carioca, Rio de Janeiro, Brazil, CEP: 21931-420, e-mail: carlos@fisiologista.com

Received: January 10, 2018

Accepted for publication: March 14, 2018

Citation: Herdy CV, Galvao P, e Silva GC, Ramos S, Simao R, Pedrinelli A, Mansur S, Goncalves D, Paschalis V. Knee flexion and extension strength in young Brazilian soccer players: the effect of age and position. Hum Mov. 2018;19(3):23-29; doi: https://doi.org/10.5114/hm.2018.76076. 
with a high predictive standard and great reliability [1, 6, 12-21], utilized by distinguished soccer clubs and research centres.

The actual soccer panorama indicates the importance of morphological, cardiovascular, and neuromuscular profiles of the players between their respective game positions [5]. However, regarding the influence of age and cumulative training time on characteristics related to the strength profile in adolescent soccer athletes, the literature is still scarce. Thus, the present study aims to compare isokinetic knee flexors and extensors concentric muscle strength (in dominant and non-dominant limbs) in Brazilian young elite soccer players of different ages and game positions.

\section{Material and methods}

\section{Participants}

Seventy-seven young male soccer players from Club de Regatas Vasco da Gama (Rio de Janeiro, Brazil) participated in the study. They were divided into 3 age categories: under 15 years of age (U-15; $n=25)$, under 17 years of age (U-17; $n=27)$, and under 20 years of age $(\mathrm{U}-20 ; n=25)$, with the consideration of 4 game positions (goalkeepers, defenders, midfielders, and forwards). To be included in the study, all subjects had to have performed isokinetic testing before the study and to present no medical history that could be aggravated by participation in resistance training. The athletes were also instructed to abstain from any nutritional or ergogenic supplements.

First, on a separate day, the participants' body weight and height were determined with the use of a weighing machine (Welmy Classe III, Brazil, 2014). Afterwards, the vertical jump test: countermovement jump with free arms was conducted with the iPhone $5 \mathrm{~s}$ app My Jump, scientifically validated with the strength platform which is considered a gold standard for evaluating vertical jump [22]. To calculate the power of vertical jump, the My Jump app uses a 120-Hz high speed camera, with $720 p$ definition to record vertical jumps, estimating the power of the lower limbs. The data necessary for the evaluations are: weight ( $\mathrm{kg}$ ), lower limbs length (centimetres), and height at $90^{\circ}$ (centimetres); the two latter measures were taken with an anthropometric measuring tape (Sanny, Brazil, 2012). The hang time of each jump was determined by the app. The test was performed in accordance with the protocol by Balsalobre-Fernández et al. [22].

Secondly, bone maturation was tested in a teleradiography examination of upper limbs, specifically of the left hand and fist. The examinations took place in a medical centre close to the organization headquarters, on 4 different days of March 2016. To estimate the bone age, the authors used the Greulich and Pyle protocol (G\&P), which consists in contrasting the obtained image with the image of the skeletal age that best corresponds to the bone characteristics found, thus estimating the biological age. The difference between the biological age and chronological age indicates if the individual is normal (chronological age $\approx$ biological age), early mature (chronological age $<$ biological age) or late mature (chronological age $>$ biological age). After this procedure, the predicted height was estimated with the BoneXpert protocol on the platform available in the Bone Expert domain [23]. All subjects were instructed to refrain from participating in any physical training during the study period, except that prescribed as part of the investigation.

\section{Isokinetic testing}

An isokinetic dynamometer (Technogym ${ }^{\circledR}$, REV 9000, Italy) was used for strength assessments. The subjects performed 5 submaximal familiarization contractions. The first limb to be tested was randomly selected. The concentric tests of the hamstrings and quadriceps were performed at $30 \%, 60 \%$ s, and $180 \%$ s with 5 maximal repetitions; the particular tests with different angular velocities were performed on distinct and non-consecutive days. In addition, the ratio of $180^{\circ} / 30^{\circ}$ was calculated [5]. A standardized pre-test procedure was employed, where all athletes received instructions on the test purposes, as well as on the procedures for performing the test. A 5-minute warm-up was carried out with the use of a cycle ergometer at the speed of $80 \mathrm{rpm}$ and mean power of $50 \mathrm{~W}$. The environmental conditions during the tests were as follows: ambient temperature of $21.8 \pm 1.20^{\circ} \mathrm{C}(20-24)$, barometric pressure of $702.7 \pm 1.4 \mathrm{~mm} \mathrm{Hg}$ (700-705), and relative humidity percentage of $52.1 \pm 14.9 \%$ (28-71). The evaluation of the isokinetic strength was undertaken in the seated position ( $120^{\circ}$ hip angle). The subjects were stabilized by belts attached to the chest, hip, and thigh of the tested limb. They crossed their arms over the chest to minimize the involvement of upper body musculature. The lateral femoral condyle was aligned with the axis of the dynamometer rotation while the ankle cuff was attached proximally to the lateral malleolus. Gravitational correction was performed to account for the limb mass. The participants were tested by the same examiner, who encouraged the athlete with verbal command throughout the test to perform with their maximal effort. 


\section{Statistical analysis}

All data are presented as means $( \pm S D)$. The Kolmogorov-Smirnov test was performed to assess normality, and Bartlett test to determine the homoscedasticity of the data. All variables presented normal distribution and homoscedasticity. Two-way ANOVA was applied with Tukey's honest significant difference tests when appropriate, to examine the differences between strength (dominant vs. non-dominant) and age (U-15 vs. U-17 vs. U-20), strength (dominant vs. non-dominant) $\times$ position (4 groups) for each age separately, muscle group (flexors vs. extensors) $\times$ age (U-15 vs. U-17 vs. U-20), muscle group (flexors vs. extensors) $\times$ position (4 groups) for each age separately, as well as to identify potential differences between the groups. The significance level was set at $p<0.05$. Data were analysed with $R$, version 3.4.2.

\section{Ethical approval}

The research related to human use has been complied with all the relevant national regulations and institutional policies, has followed the tenets of the Declaration of Helsinki, and has been approved by the Research Ethics Committee of the Federal University of Rio de Janeiro, with the number 34315478.7.0000.5257, in accordance with Resolution 196/96 of the Brazilian Health Council.

\section{Informed consent}

Informed consent has been obtained from all individuals included in this study and their respective legal guardians in accordance with the ethics standards of the Brazilian Health Council.

\section{Results}

The results of the initial measurements are presented in Table 1.

The U-20 athletes revealed the greatest quadriceps torque values (concentric) compared with the other categories, whereas the U-15 had the lowest values (Table 2). The goalkeepers presented the highest quadriceps torque values (concentric) compared with

Table 1. Characteristics of athletes divided by categories

\begin{tabular}{lccc}
\hline Characteristics & $\mathrm{U}-15$ & $\mathrm{U}-17$ & $\mathrm{U}-20$ \\
\hline Number of subjects $(n)$ & 25 & 27 & 25 \\
Age (years) & $15.2 \pm 0.4$ & $16.8 \pm 0.6$ & $19.1 \pm 0.8$ \\
Mass (kg) & $64.9 \pm 9.3$ & $73.1 \pm 7.5$ & $74.4 \pm 10.0$ \\
Height (m) & $1.7 \pm 0.1$ & $1.8 \pm 0.1$ & $1.8 \pm 0.1$ \\
Maturation status & Normal & Normal & Normal \\
My Jump test (watts) & $2386.6 \pm 561.3$ & $2708.8 \pm 411.7$ & $2826.5 \pm 344.3$ \\
$\mathrm{VO}_{2 \text { max }}$ (ml $\left.\cdot \mathrm{kg} \cdot \mathrm{min}\right)$ & $51.3 \pm 1.0$ & $55.3 \pm 2.2$ & $54.5 \pm 3.1$ \\
\hline
\end{tabular}

Table 2. Means and standard deviations of quadriceps torque values (concentric) at different angular velocities, relative to category

\begin{tabular}{|c|c|c|c|}
\hline & & & \\
\hline & $\mathrm{U}-15(n=25)$ & $\mathrm{U}-17(n=27)$ & $\mathrm{U}-20(n=25)$ \\
\hline \multicolumn{4}{|l|}{ Dominant } \\
\hline $30 \% \mathrm{~s}$ & $151.2 \pm 61.0^{*}$ & $169.7 \pm 57.6$ & $186.9 \pm 62.1$ \\
\hline $60 \% \mathrm{~s}$ & $142.7 \pm 50.3^{*}$ & $172.2 \pm 48.5^{* *}$ & $188.7 \pm 52.8$ \\
\hline $180 \% \mathrm{~s}$ & $125.9 \pm 40.9^{*}$ & $157.7 \pm 44.1 * *$ & $174.6 \pm 45.1 * * *$ \\
\hline $180^{\circ} / 30^{\circ}$ & $0.8 \pm 0.1$ & $0.9 \pm 0.1$ & $0.9 \pm 0.1$ \\
\hline \multicolumn{4}{|c|}{ Non-dominant } \\
\hline $30 \% \mathrm{~s}$ & $144.4 \pm 57.5^{*}$ & $162.1 \pm 54.2$ & $179.1 \pm 63.1$ \\
\hline $60 \% \mathrm{~s}$ & $140.2 \pm 50.9^{*}$ & $166.7 \pm 50.3^{* *}$ & $181.0 \pm 59.8$ \\
\hline $180 \% \mathrm{~s}$ & $131.5 \pm 43.1^{*}$ & $152.9 \pm 44.1 * *$ & $168.7 \pm 45.7 * * *$ \\
\hline $180^{\circ} / 30^{\circ}$ & $0.9 \pm 0.1$ & $0.9 \pm 0.1$ & $0.9 \pm 0.1$ \\
\hline
\end{tabular}

* significant difference $(p<0.01)$ between $\mathrm{U}-15$ and U-20

** significant difference $(p<0.01)$ between U-15 and U-17

*** significant difference $(p<0.05)$ between U-17 and U-20 


\section{HUMAN MOVEMENT}

C.V. Herdy et al., Knee strength in young soccer players

Table 3. Means and standard deviations of quadriceps torque values (concentric) at different angular velocities, relative to position

\begin{tabular}{|c|c|c|c|c|}
\hline & \multirow{2}{*}{ Goalkeepers } & \multirow{2}{*}{ Defenders } & \multirow{2}{*}{ Midfielders } & \multirow{2}{*}{ Forwards } \\
\hline & & & & \\
\hline \multicolumn{5}{|l|}{ Dominant } \\
\hline $30 \% \mathrm{~s}$ & $206.4 \pm 70.6$ & $168.3 \pm 64.4^{*}$ & $164.4 \pm 56.5^{*}$ & $160.1 \pm 54.3 *$ \\
\hline $60 \% / \mathrm{s}$ & $207.7 \pm 55.5$ & $168.9 \pm 53.0^{*}$ & $160.8 \pm 52.3^{*}$ & $157.2 \pm 49.0^{*}$ \\
\hline $180^{\circ} / \mathrm{s}$ & $202.3 \pm 48.7$ & $153.0 \pm 45.9^{*}$ & $144.1 \pm 42.3^{*}$ & $140.8 \pm 43.3^{*}$ \\
\hline $180^{\circ} / 30^{\circ}$ & $0.9 \pm 0.1$ & $0.8 \pm 0.1$ & $0.8 \pm 0.1$ & $0.8 \pm 0.2^{* *}$ \\
\hline \multicolumn{5}{|c|}{ Non-dominant } \\
\hline $30 \% \mathrm{~s}$ & $200.3 \pm 70.7$ & $158.0 \pm 61.0^{*}$ & $157.9 \pm 54.7^{*}$ & $155.7 \pm 52.9^{*}$ \\
\hline $60 \% \mathrm{~s}$ & $209.7 \pm 60.7$ & $158.7 \pm 55.9^{*}$ & $155.8 \pm 51.3^{*}$ & $155.7 \pm 48.6^{*}$ \\
\hline $180^{\circ} / \mathrm{s}$ & $194.4 \pm 52.6$ & $148.3 \pm 44.0^{*}$ & $144.3 \pm 42.0^{*}$ & $144.5 \pm 44.5^{*}$ \\
\hline $180^{\circ} / 30^{\circ}$ & $0.9 \pm 0.1$ & $0.9 \pm 0.1$ & $0.9 \pm 0.1$ & $0.9 \pm 0.1^{* *}$ \\
\hline
\end{tabular}

* significant difference $(p<0.05)$ between goalkeepers and defenders/midfielders/forwards

*** significant difference $(p<0.01)$ between goalkeepers and forwards

Table 4. Means and standard deviations of hamstring torque values (concentric) at different angular velocities, relative to category

\begin{tabular}{lccc}
\cline { 2 - 3 } & $\mathrm{U}-15(n=25)$ & $\mathrm{U}-17(n=27)$ & $\mathrm{U}-20(n=25)$ \\
\hline Flexors & & & \\
$30 \% \mathrm{~s}$ & $191.5 \pm 48.9^{*}$ & $212.9 \pm 34.8^{* *}$ & $233.7 \pm 44.1^{* * *}$ \\
$60^{\circ} / \mathrm{s}$ & $177.2 \pm 40.9^{*}$ & $209.7 \pm 29.5^{* *}$ & $228.3 \pm 39.7^{* * *}$ \\
$180^{\circ} / \mathrm{s}$ & $156.9 \pm 35.5^{*}$ & $188.9 \pm 31.0^{* *}$ & $201.8 \pm 34.3^{* * *}$ \\
$180^{\circ} / 30^{\circ}$ & $0.8 \pm 0.1$ & $0.9 \pm 0.1$ & $0.9 \pm 0.1$ \\
\hline Extensors & & & \\
$30 \% \mathrm{~s}$ & $104.2 \pm 27.8^{*}$ & $118.9 \pm 24.0^{* *}$ & $132.2 \pm 25.7^{* * *}$ \\
$60^{\circ} / \mathrm{s}$ & $105.6 \pm 28.9^{*}$ & $128.5 \pm 22.8^{* *}$ & $141.4 \pm 31.4^{* * *}$ \\
$180^{\circ} / \mathrm{s}$ & $100.5 \pm 25.7^{*}$ & $121.7 \pm 25.4^{* *}$ & $141.5 \pm 33.3^{* * *}$ \\
$180^{\circ} / 30^{\circ}$ & $0.9 \pm 0.1$ & $0.9 \pm 0.1$ & $0.9 \pm 0.1$ \\
\hline
\end{tabular}

* significant difference $(p<0.01)$ between U-15 and U-20

** significant difference $(p<0.01)$ between U-15 and U-17

*** significant difference $(p<0.05)$ between $\mathrm{U}-17$ and U-20

Table 5. Means and standard deviations of hamstring torque values (concentric) at different angular velocities, relative to position

\begin{tabular}{|c|c|c|c|c|}
\hline & & & & \\
\hline & Goalkeepers & Defenders & Midfielders & Forwards \\
\hline \multicolumn{5}{|l|}{ Flexors } \\
\hline $30 \% \mathrm{~s}$ & $260.9 \pm 48.2$ & $212.3 \pm 45.9^{*}$ & $205.3 \pm 39.5^{*}$ & $200.5 \pm 39.0^{*}$ \\
\hline $60 \% \mathrm{~s}$ & $250.4 \pm 45.9$ & $205.3 \pm 41.2^{*}$ & $195.9 \pm 39.3^{*}$ & $195.8 \pm 32.7^{*}$ \\
\hline $180^{\circ} / \mathrm{s}$ & $230.6 \pm 45.2$ & $183.0 \pm 33.1^{*}$ & $170.3 \pm 32.3^{*}$ & $175.3 \pm 34.3^{*}$ \\
\hline $180^{\circ} / 30^{\circ}$ & $0.9 \pm 0.1$ & $0.9 \pm 0.1$ & $0.8 \pm 0.1$ & $0.9 \pm 0.2$ \\
\hline \multicolumn{5}{|l|}{ Extensors } \\
\hline $30 \% \mathrm{~s}$ & $145.7 \pm 24.5$ & $114.0 \pm 29.9^{*}$ & $117.1 \pm 25.8^{*}$ & $115.3 \pm 22.5^{*}$ \\
\hline $60 \% \mathrm{~s}$ & $166.9 \pm 30.7$ & $122.3 \pm 28.3^{*}$ & $120.7 \pm 30.8^{*}$ & $117.0 \pm 22.4^{*}$ \\
\hline $180^{\circ} \mathrm{s}$ & $166.1 \pm 30.1$ & $118.2 \pm 28.8^{*}$ & $118.1 \pm 33.5^{*}$ & $110.0 \pm 22.1^{*}$ \\
\hline $180^{\circ} / 30^{\circ}$ & $0.9 \pm 0.1$ & $0.9 \pm 0.1$ & $0.9 \pm 0.1$ & $0.9 \pm 0.1$ \\
\hline
\end{tabular}

${ }^{*}$ significant difference $(p<0.01)$ between goalkeepers and defenders/midfielders/forwards 
the other game positions, whereas the values were smallest among the forwards (Table 3).

The U-20 athletes revealed the greatest hamstring torque values (concentric) compared with the other categories, whereas the U-15 had the lowest values (Table 4). The goalkeepers presented the highest hamstring torque values (concentric) compared with the other game positions, whereas the values were smallest among the forwards (Table 5).

\section{Discussion}

The purpose of the present study was to compare the concentric isokinetic muscle strength (dominant and non-dominant limb) in young Brazilian elite soccer players of different age categories and game positions. The main findings suggest that players allocated in different categories have different isokinetic profiles, demonstrating significant differences between the strength levels in the categories of U-15, U-17, and U-20. In addition, the volunteer players for the analysis of the study did not present the same relationships in the non-dominant leg, which generally had lower levels of strength. Goalkeepers, in particular, demonstrated higher strength compared with other game positions, although defenders also presented significant values; this suggests the importance of individualized and specific training for each position.

Regarding the results of the concentric isokinetic torque values of quadriceps, illustrated in Table 2, we observed that the U-15 players presented significantly lower values in comparison with the U-20 athletes at the angular velocities of $30 \% \mathrm{~s}, 60 \%$, and $180 \% \mathrm{~s}$ in both limbs; no difference occurred in the $180^{\circ} / 30^{\circ}$ ratio. It seems that U-17 athletes, because they did not present a significant difference of concentric isokinetic quadriceps torque in comparison with the U-20 athletes, have similar strength levels, which could suggest that they would be ready to receive loads of similar magnitude for this musculature. However, significant differences for the $180 \%$ s velocity were observed in dominant and non-dominant legs, suggesting that the concentric isokinetic muscle strength differences between categories are expressed in both legs. According to Herdy et al. [24] and Lehance et al. [25], balance between musculature and limbs is essential to preventing injuries.

In this sense, also according to Lehance et al. [25], such imbalances can be an important indicator of injury. With respect to the values obtained by analysing the torque of concentric hamstrings (Table 4), it was observed that U-15 athletes had power levels signifi- cantly lower than the U-20 ones in all investigated angular velocities. However, the analysis of the $180^{\circ} / 30^{\circ}$ ratio demonstrated that the force levels were not significantly different among the 3 age categories (U-15, U-17, and U-20). Therefore, although they may present some similarities in the production of isokinetic strength, U-15 athletes do not have the same strength level as U-17 and U-20 athletes, signalling the necessity of an intentional and differentiated intervention by age category.

Additionally, our data also point to a professional action varied with regard to the game positions. Goalkeepers, according to Tables 3 and 5, presented concentric muscular torque levels (quadriceps and hamstrings) significantly higher than the other game position athletes, regardless of the angular velocity used. Lago-Peñas et al. [26] and Gil et al. [27] also highlighted the fact that goalkeepers had different strength levels from other athletes, given their specificity of training. Herdy et al. [24] corroborated our findings in a study involving U-17, U-20, and professional athletes, demonstrating that goalkeepers had neuromuscular and physiological profiles distinct from players of the other game categories.

On the other hand, in conflict with the present findings, Tsiokanos et al. [5] reported no differences between field positions after examining the concentric isokinetic torque peak in professional Greek soccer players. Such divergences occurred probably because Tsiokanos et al. [5] studied professional athletes, while the present study undertook an analysis of U-15, U-17, and U-20 categories. In addition, Tsiokanos et al. [5] investigated only the dominant leg, which may have been a limiting factor for inferences. Thus, our results point to the need for specific training addressed to different categories and positions. Similar findings were obtained in the classic study by Oberg et al. [28], where goalkeepers had greater knee extension strength than attackers because of genetic factors or differences in training. More specifically, goalkeeper training includes a large number of jumps and vertical movements at different speeds, which almost always require strong knee extension and/or flexion.

In this context, the present results also point out that defenders produce significantly more concentric quadriceps strength as compared with midfielders. The average values of isokinetic strength in the defenders were higher than among players of the other positions, except goalkeepers. Football is a complex sport, where playing and training in a certain position can promote different levels of muscular strength. Possibly, chronic defensive soccer training actions generate high levels 
of strength. However, this relationship is not well described in the literature and needs further investigation. Therefore, observation and analysis of the age categories and positions performed in the field are of great importance for professionals seeking to achieve the best results and prevention of injuries [29-31].

Finally, the present study has some limitations that may restrict inferences. For example, only players of an elite club of the Brazilian soccer of the first division participated in the investigation. Considering its competitiveness and the fact that the teams of this club participate successfully in state, national, and international championships, the conclusions can be applied in a global perspective. However, we admit the need to carry out parallel studies involving the analysed categories and positions, but in other countries, in order to extrapolate the results. Besides, using the absolute peak torque is significant, as the comparison of the relative peak torque could infer different results, since it is influenced by body weight and limb length, characteristics that depend on the maturation process. In this regard, we also recommend broadening the scope of the research by including other muscle groups, as well as other variables with potential association.

\section{Conclusions}

Players of different categories present different profiles, and the U-15, U-17, and U-20 athletes do not have the same level of isokinetic strength. In addition, the studied players did not demonstrate regular values between the dominant and non-dominant limb: the dominant leg showed more strength in general. Especially the goalkeepers revealed high strength values, which suggests the importance of specific training for each position game athletes.

Professionals involved in soccer training are therefore alerted to review the training and rehabilitation procedures applied with younger players and to consider tailoring these to the athlete's playing position, raising concern in bilateral activities aimed to reduce differences between legs and musculatures.

Finally, further and more controlled research is recommended to extrapolate the present data and establish relationships among the respective values in athletes from other countries and sports.

\section{Disclosure statement}

No author has any financial interest or received any financial benefit from this research.

\section{Conflict of interest}

The authors state no conflict of interest.

\section{References}

1. Gioftsidou A, Ispirlidis I, Pafis G, Malliou P, Bikos C, Godolias G. Isokinetic strength training program for muscular imbalances in professional soccer players. Sport Sci Health. 2008;2(3):101-105; doi: 10.1007/ s11332-008-0047-5.

2. Reilly T, Clarys J, Stibbe A. Introduction. In: Reilly T, Clarys J, Stibbe A (eds.), Science and football II. London: E-FN Spon; 1993; xix-xx.

3. Burke LM, Hawley JA. Fluid balance in team sports. Guidelines for optimal practices. Sports Med. 2007; 24(1):38-54; doi: 10.2165/00007256-199724010-00004.

4. Brown LE, Weir JP. ASEP Procedures recommendation I: accurate assessment of muscular strength and power. J Exerc Physiol. 2001;4(3):1-21.

5. Tsiokanos A, Paschalis V, Valasotiris K. Knee extension strength profile of elite Greek soccer players. Isokinetics Exerc Sci. 2016;24(1):79-82; doi: 10.3233/ IES-150603.

6. Hamzeh M, Head A. Isokinetic hamstrings and quadriceps evaluation of professional soccer players. J Sports Sci. 2004;22(3):265-266.

7. Silva JF, Detanico D, Floriano LT, Dittrich N, Nascimento PC, Santos SG, et al. Levels of muscle power in soccer and futsal athletes in different categories and positions [in Portuguese]. Motricidade. 2012;8(1):1422; doi: 10.6063/motricidade.8(1).233 .

8. Caruso JF, Coday MA, Ramsey CA, McLagan JR. The impact of resistive exercise training on the relationship between anthropometry and jump-based power indices. Isokinet Exerc Sci. 2009;17(1):41-50; doi: 10.3233/IES-2009-0331.

9. Malliou P, Ispirlidis I, Beneka A, Taxildaris K, Godolias G. Vertical jump and knee extensors isokinetic performance in professional soccer players related to the phase of the training period. Isokinet Exerc Sci. 2003; 11(3):165-169.

10. Dauty M, Bryand F, Potiron-Josse M. Relation between isokinetic torque, jump and sprint in high-level soccer player [in French]. Sci Sports. 2002;17(3):122-127; doi: 10.1016/S0765-1597(02)00137-5.

11. Wisløff J, Helgerud J, Hoff J. Strength and endurance of elite soccer players. Med Sci Sports Exerc. 1998;30(3): 462-467; doi: 10.1097/00005768-199803000-00019.

12. Capranica L, Cama G, Fanton F, Tessitore A, Figura F. Force and power of preferred and non-preferred leg in young soccer players. J Sports Med Phys Fitness. 1992; 32(4):358-363.

13. Agre JC, Baxter TL. Musculoskeletal profile of male collegiate soccer players. Arch Phys Med Rehabil. 1987; 68(3):147-150.

14. Gür H, Akova B, Pündük Z, Küçükoğlu S. Effects of age on the reciprocal peak torque ratios during knee muscles contractions in elite soccer players. Scand J Med Sci Sports. 1999;9(2):81-87; doi: 10.1111/j.1600-0838.1999. tb00213.x. 
15. Tourny-Chollet C, Leroy D, Léger HL, Beuret-Blanquart F. Isokinetic knee muscle strength of soccer players according to their position. Isokinet Exerc Sci. 2000;8(4):187-193.

16. Mangine R, Noyes FR, Mullen MP, Barber-Westin SD. A physiological profile of the elite soccer athlete. J Orthop Sports Phys Ther. 1990;12(4):147-152; doi: 10.2519/ jospt.1990.12.4.147.

17. Zakas A, Galazoulas C, Doganis G, Zakas N. Effect of two acute static stretching durations of the rectus femoris muscle on quadriceps isokinetic peak torque in professional soccer players. Isokinet Exerc Sci. 2006;14(4): 357-362.

18. Croisier JL, Reveillon V, Ferret JM, Cotte T, Genty M, Popovich N, et al. Isokinetic assessment of knee flexors and extensors in professional soccer players. Isokinet Exerc Sci. 2003;11(1):61-62.

19. Tourny-Chollet C, Leroy D, Delarue Y, Beuret-Blanquart F. Isokinetic-based comparison of hamstringsquadriceps ratio between soccer players and sedentary subjects. Isokinet Exerc Sci. 2003;11(1):85-86.

20. Nikolaidou ME, Rousanoglou EN, Bayios IA, Boudolos KD. Athletic specialization of young males and relationships of elbow extensor and flexor muscular strength. Isokinet Exerc Sci. 2006;14(4):307-315.

21. Holm I, Steen H, Olstad M. Isokinetic muscle performance in growing boys from pre-teen to maturity. An eleven-year longitudinal study. Isokinet Exerc Sci. 2005;13(2):153-158.

22. Balsalobre-Fernández C, Glaister M, Lockey RA. The validity and reliability of an iPhone app for measuring vertical jump performance. J Sports Sci. 2015;33(15): 1574-1579; doi: 10.1080/02640414.2014.996184.

23. Thodberg HH, Kreiborg S, Juul A, Pedersen KD. The BoneXpert method for automated determination of skeletal maturity. IEEE Trans Med Imaging. 2009;28(1): 52-66; doi: 10.1109/TMI.2008.926067.

24. Herdy C, Vale R, da Silva J, Simão R, Novaes J, Lima V, et al. Occurrence and type of sports injuries in elite young Brazilian soccer players. Arch Med Deporte. 2017;34(3):140-144.

25. Lehance C, Binet J, Bury T, Croisier JL. Muscular strength, functional performances and injury risk in professional and junior elite soccer players. Scand J Med Sci Sports. 2009;19(2):243-251; doi: 10.1111/j.1600-0838.2008. 00780.x.

26. Lago-Peñas C, Casais L, Dellal A, Rey E, Domínguez E. Anthropometric and physiological characteristics of young soccer players according to their playing positions: relevance for competition success. J Strength Cond Res. 2011;25(12):3358-3367; doi: 10.1519/JSC.0b013e318 $216305 d$.

27. Gil SM, Gil J, Ruiz F, Irazusta A, Irazusta J. Physiological and anthropometric characteristics of young soccer players according to their playing position: relevance for the selection process. J Strength Cond Res. 2007;21(2):438-445; doi: 10.1519/R-19995.1.
28. Oberg B, Ekstrand J, Möller M, Gillquist J. Muscle strength and flexibility in different positions of soccer players. Int J Sports Med. 1984;5(4):213-216; doi: 10.1055/s-2008-1025908.

29. Van Dyk N, Bahr R, Whiteley R, Tol JL, Kumar BD, Hamilton B, et al. Hamstring and quadriceps isokinetic strength deficits are weak risk factors for hamstring strain injuries: a 4-year cohort study. Am J Sports Med. 2016;44(7):1789-1795; doi: 10.1177/0363546516632526.

30. Ksibi I, Kessomtini W, Ilehi Y, Maaoui R, Rahali Khachlouf H. Isokinetic profile of knee muscles in Tunisian competitive footballers [in French]. Tunis Med. 2015;93(5):322-325.

31. Ardern CL, Pizzari T, Wollin MR, Webster KE. Hamstrings strength imbalance in professional football (soccer) players in Australia. J Strength Cond Res. 2015; 29(4):997-1002; doi: 10.1519/JSC.0000000000000747. 